\title{
A Study of Relationship between Perfectionism and Academic Achievement of Chinese University Students from the Perspectives of Variable-centered and Person-centered Analysis
}

\author{
Liu Guirong, Teng Xiuqin*, Lu Chun, Yang Kun \\ Teacher Education Department, Qilu Normal University, Jinan 250200
}

\begin{abstract}
In order to investigate the impact of perfectionism on academic achievement of Chinese university students, this study adopted the method of variable-centered and personcentered analyses. The Chinese Frost Multidimensional Perfectionism Scale (CFMPS), which includes positive perfectionism (PP) and negative perfectionism (NP) was performed on 291 college students from two universities, and their academic achievement was acquired from the school deans' offices. The variable-centered analysis results indicate that positive perfectionism prediction results are positive; personcentered analysis results indicate that moderate PP/low NP is the most common, accounting for $30.2 \%$. In terms of academic achievement, high PP/moderate NP, moderate PP/low NP, and moderate PP/moderate NP perform better than other types.
\end{abstract}

Keywords-Positive perfectionism; Negative perfectionism; Academic achievement

\section{INTRODUCTION}

Students' academic achievement is an important indicator of student's adaptability to life [1], so for college students, the academic achievement, especially that of the professional core curriculum, acts as an important basis to measure the academic level of college students. There are many factors that affect the academic performance of college students, and more and more researchers pay attention to the impact of personality traits on the academic achievement of students [2-3]. In the personality traits, perfectionism has a great impact on academic achievement [4-6].

Perfectionism is a personality trait and a way of thinking, seeking to perform tasks perfectly and accompanied by critical self-evaluations [7]. In recent years, more and more researchers accept that perfectionism is a multidimensional structure. For example, Frost believes that perfectionism includes five dimensions such as organization (OR), personal standards (PS), doubts about actions (DA), parental expectations (PE), and concern over mistakes (CM). Based on the multidimensional perspective, more and more researchers propose that perfectionism should not be considered simply and entirely as destructive and negative, and that positive and healthy perfectionism also exists. According to this, positive perfectionism and negative perfectionism are differentiated [8]
[9]. Positive perfectionism has a high PS but less CM, correlating with proactive management and responsibility [10], while negative perfectionism is overly concerned over mistakes and of self-doubt, whose motives are fear of failure and social criticism [11]. The latter is self-defeating [12]

When discussing the impact of some perfectionism on academic achievement, most of the previous studies only examined the impact of a certain perfectionism, trying to answer the question of what kind of perfectionism is more beneficial to improve students' academic achievement. Although both positive and negative perfectionists are struggling to achieve their goals, the research shows that the positive perfectionism positively predicts Academic Achievement [6]. Such study is based on the variablecentered perspective [6] [13], helping to analyze the relationship between different perfectionism and academic achievement.

However, there is not only one kind of perfectionism for individuals but a combination of the two main perfectionism at different levels, so the past variable-centered approach hardly reflects the real situation of individuals. Some researchers investigate the differences between various types of perfectionists from the person-centered perspective and find that there may exist varied combinations of perfectionism types for an individual [11]. In view of this, this study will proceed from the individual center through empirical research to examine the predictive role of the two main perfectionism in academic achievement in those combinations.

Although the research paradigms of variable and individual centers differ in goals, strategies and theoretical assumptions, results obtained by the two paradigms can complement and confirm each other so as to enable the researchers to gain a comprehensive understanding of a problem [14-15]. Therefore, this study attempts to explore the following problems from the variable-centered and person-centered perspectives: (1) the predicative function of two major perfectionism (positive perfectionism and negative perfectionism) to academic achievement; (2) How dose the two different perfectionism combine for an individual, and what several types do these combination models separate individuals into? (3) Is there any difference in academic achievement for different combinations? 


\section{METHOD}

\section{A. Participants}

Using the cluster random sampling method, 312 sophomores and seniors altogether from 9 classes are selected from two universities in Jinan City, Shandong Province. After removing invalid questionnaires, 291 valid questionnaires are obtained (response rate 93.27\%). In this survey, there are 102 boys and 189 girls, who are aged $19.91 \pm 0.62$ years old.

\section{B. Measures}

This study employs the Chinese Frost Multidimensional Perfectionism Scale (CFMPS), originally developed by Frost and acting as the most commonly used tool for measuring perfectionism. Zi Fei and Zhou Xu (2006) revised the Chinese version of the questionnaire [16]. The questionnaire consists of 27 questions, divided into five dimensions: organization, personal standards, doubts about actions, parental expectations, and concern over mistakes. The 6 questions about "organization" are used to measure positive perfectionism, while the other 21 questions about "personal standards", "doubts about actions", "parental expectations" , and concern over mistakes are used to measure negative perfectionism. The questionnaire utilizes a scale of 1 to 5 , with 1 indicating "no consistency", 2 " a little consistency ", 3 "uncertainty", 4 "consistency", and 5 "great consistency". In this study, confirmatory factor analysis is conducted with Lisrel 8.70, greatly fitting: $\chi^{2} / d f=1.47, N N F I=0.99, C F I=0.98, N F I=$ $0.98, R M S E A=0.04$; the internal consistency coefficient of organization, personal standards, doubts about actions, parental expectations and concern over mistakes are $0.83,0.74,0.66$, 0.60 and 0.83 , respectively, as well as the overall reliability of the questionnaire is 0.83 .

Academic achievement is obtained from the three representative subjects of the last final exam of a college student; As a result of different majors and terms, subject grades used are as follows: for the primary educational major, grades of primary English, primary Chinese and language and theory of moral education; for preschool education major, grades of preschool children's social education, preschool children's health education and preschool children's science education; for the financial management major, grades of statistics, security analysis and investment, and financial statement analysis; for the marketing major, grades of ecommerce, service marketing and financial management; for the economics and finance major, grades of statistics, advanced financial management, and assets appraisal. Then standardize each grade on a class basis, get the $Z$ scores of the three subjects, and take the average of the three $\mathrm{Z}$ scores as the students' academic achievement.

\section{Procedure}

Before the formal test, train all the experimenters in instructions and test notes. Experimenters consists of trained students majored in psychology and full-time teachers. Take the overall implementation of the test method, so unifiedly send and collect questionnaires. Use SPSS16.0 and LISREL8.70 to analyze data.

\section{RESULTS}

\section{A. Descriptive Statistics for Each Variable}

In order to investigate the possible differences among college students in terms of gender, grades and majors, this study uses gender, grades, and majors as independent variables, with positive perfectionism, negative perfectionism and academic achievement as dependent variables, and makes a $2 \times$ $2 \times 5$ multiple variance analysis. Results show that there are significant differences in academic achievement between male and female students, $F(1,290)=4.43, p<0.05, \eta^{2}=0.02$; female students' academic achievement $(M=0.06, S D=0.77)$ is higher than male students' $(M=-0.51, S D=0.71)$. Academic achievement does not differ significantly in grades and majors; there is no difference among gender, grades and majors for perfectionism; interaction of gender, grades, and majors is nonsignificant for each variable.

The descriptive statistics and related analysis results of participants in all variables are shown in Table 1.

TABLE I. DESCRIPTIVE STATISTICS FOR EACH VARIABLE AND ITS CORRELATION MATRIX

\begin{tabular}{lccc}
\hline & 1 & 2 & 3 \\
\hline 1.Positive Perfectionism & 1 & & \\
2. Negative Perfectionism & $.12^{*}$ & 1 & 1 \\
3. Grade & $.17^{* *}$ & -.04 & .00 \\
$M$ & 4.09 & 2.73 & .78 \\
$S D$ & .71 & .56 & \\
\hline
\end{tabular}

From the correlation matrix in Table 1, there is a significant positive correlation between positive perfectionism and academic achievement $(r=0.17, p<0.01)$; there is no significant correlation between negative perfectionism and academic achievement; positive perfectionism is positively correlated with negative perfectionism $(r=0.12, p<0.05)$.

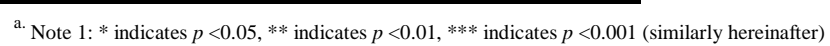

\section{B. Relationship Between Positive-Negative Perfectionism} and Academic Achievement: Variable-centered Analysis

In regression analysis, this study explores the relationship between positive perfectionism, negative perfectionism, interaction of positive and negative perfectionism, and academic achievement, namely multivariate regression analysis 
with positive perfectionism, negative perfectionism and their interaction as independent variables. Results show that negative perfectionism has no significant effect on the prediction of academic achievement $(\beta=-0.09, p>0.05)$; positive perfectionism significantly positively predicts academic achievement $(\beta=0.18, p<0.01)$; interaction of positive and negative perfectionism has no significant predictive effect on academic achievement $(\beta=0.02, p>0.05)$. The entire model can explain a $3.2 \%$ variation in academic achievement.

\section{Relationship Between Positive-Negative Perfectionism and Academic Achievement: Person-centered Analysis}

Two kinds of perfectionism (positive and negative) are used as analysis variables, and the college students' academic achievement as analysis data for cluster analysis. Cluster analysis shows that the model is the best when the data are clustered into 5 categories according to the minimum criterion of BIC $=(260.78)$. The first category is perfectionists of high $\mathrm{PP} /$ moderate NP (76 persons, $26.1 \%$ ), the second perfectionists of moderate PP/low NP (88 persons, 30.2\%), the third perfectionists of moderate $\mathrm{PP} /$ moderate NP (81 persons, $27.8 \%$ ), the fourth perfectionists of moderate PP/high NP (15 persons, 5.2\%), and the fifth perfectionists of low PP/Low NP (31 persons, 10.7\%). Taken together, moderate PP/low NP perfectionists are the most common, accounting for $30.2 \%$ of all types. Scores of the five perfectionism types are shown in Table 2.

TABLE II. Statistical Results of the Five PeRfectionism Types

\begin{tabular}{lccc}
\hline & $\begin{array}{c}\text { Positive Perfectionism } \\
(\text { PP })\end{array}$ & $\begin{array}{c}\text { Negative } \\
\text { Perfectionism } \\
(\text { NP) }\end{array}$ & $\begin{array}{c}\text { Academic } \\
\text { Achievement }\end{array}$ \\
\hline High PP/Moderate NP & $4.71 \pm 0.25$ & $3.03 \pm 0.30$ & $0.14 \pm 0.75$ \\
Moderate PP/Low NP & $4.29 \pm 0.46$ & $2.19 \pm 0.23$ & $0.12 \pm 0.72$ \\
Moderate PP/Moderate NP & $3.79 \pm 0.26$ & $2.89 \pm 0.27$ & $-0.06 \pm 0.83$ \\
Moderate PP/High NP & $4.15 \pm 0.56$ & $4.19 \pm 0.55$ & $-0.42 \pm 0.71$ \\
Low PP/Low NP & $2.60 \pm 0.60$ & $2.56 \pm 0.54$ & $-0.43 \pm 0.78$ \\
\hline
\end{tabular}

Table 2 describes the academic achievement scores for different perfectionism types.

ANOVA analysis shows that under different perfectionism there is a significant difference in academic achievement among college students, $F=4.26, p<0.01$. Post hoc tests show that high positive-middle negative perfectionists, middle positive-low negative perfectionists and middle positive / middle negative perfectionists have significantly higher academic achievement than middle positive-high negative perfectionists and low positive-low negative perfectionists ( $p s$ $<0.05)$; academic achievement difference among other perfectionists is not significant ( $p s>0.05)$.

\section{DISCUSSION}

Based on the question that how different perfectionism affects academic achievement of college students, this study uses the variable-centered and person-centered analysis methods to discuss the relationship between perfectionism and academic achievement of college students from two perspectives, thereby gaining some different but complementary study results. This study finds that positive perfectionism significantly positively predicts academic achievement, which is consistent with the results of previous studies [6]. This shows that positive perfectionism can promote students to be more positive, strive to accomplish the task, improve self-satisfaction and guide students to achieve selftranscendence, which can improve the academic achievement. Negative perfectionism does not significantly predict academic achievement, which is consistent with the existing findings [13].
Through analyzing person-centered results in this study, it is found that there are five different combinations of perfectionism, of which moderate PP/low NP perfectionists are the most. This reveals the characteristics of perfectionism for college students.

The study also finds that the high positive-middle negative perfectionists, the middle positive-low negative and the middle positive-middle negative ones have significantly higher academic achievement than the middle positive-high negative perfectionists and the low positive-low negative ones. This shows that under different combination of perfectionism, as long as the level of positive perfectionism is higher than that of negative perfectionism, the development of students' studies can be better promoted. At the same time, person-centered analysis also identifies the best perfectionism types that favor college students' academic achievement, namely high/middle positive-middle/low negative perfectionism types. This provides a certain degree of complement to the previous variable-centered analysis results and further enriches the existing studies of relationship between perfectionism and academic achievement.

The study results have some practical significance. In the practice of education and teaching, educators should create a harmonious and positive educational atmosphere in order to enable students to achieve better academic achievement and guide students to the positive aspects of perfectionism. 


\section{CONCLUSIONS}

This study draws the following conclusions:

(1) Positive perfectionism positively predicts the academic achievement of college students; negative perfectionism does not significantly predict academic performance.

(2) Moderate PP/Low NP is the commonest one, accounting for $30.2 \%$ of all types.

(3) The combination of high/middle positive and middle/low negative perfectionism types are the most conducive to the improvement of academic achievement of college students.

\section{ACKNOWLEDGMENT}

This paper is the result of college student scientific researching fund projects of Qilu Normal University "research on relationship between college students' academic procrastination, perfectionism and cell phone addiction" (XS2015W07), supported by the research project of social science research plan of Shandong Province "research on the impact of family system on migrant children adaptation" (17CJYJ08), "research on the impact of peer relationship on migrant children adaptation" (15CJYJ04), and by educational reform of Qilu Normal University "The application research of flipped classroom in university teaching — taking English in psychology as an example"(jg201703), and by bilingual teaching project of Qilu Normal University "English in psychology"(sykc201702), "curriculum and teaching theory in Primary English”(sykc201701).

Corresponding author: Teng Xiuqin, Email: winterqintx@126.com.

\section{REFERENCES}

[1] Liu Guirong, Zhang Jinghuan. Features and Tendencies of Educational Study__ Based on the Essays Published from 2011 to 2015. Journal of Shandong Normal University (Humanities and Social Sciences Edition), 2017,62 (4), pp. 123-132.

[2] Zhou Yangen, Sang Qingsong, Ge Minggui. Studies on the Relationship between College Students' Autonomous Learning, Achievement Goals and Academic Achievement. Psychological Science, 2010, 33 (1), pp. 194-197.

[3] Zhao Shuyuan, Cai Taisheng, Chen Zhijian. Relationship between Academic Sentiment and Academic Achievement of College Students. Chinese Journal of Clinical Psychology, 2012, 20 (3), pp.398-400.

[4] Bieling, P. J., Israeli, A., Smith, J., \& Antony, M. M. Making the grade: The behavioral consequences of perfectionism in the classroom. Personality and Individual Differences, 2003, 35(1), pp.163-178.

[5] Stoeber, J. \& Eismann, U. Perfectionism in young musicians: Relations with motivation, effort, achievement, and distress. Personality and Individual Differences, 2007, 43(8), pp.2182-2192.

[6] Thorpe, E. \& Nettelbeck, T. Testing if healthy perfectionism enhances academic achievement in Australian secondary school students. Journal of Educational and Developmental Psychology, 2014, 4(2), pp.1- 9.

[7] Zi Fei. The History and Current Status of Perfectionism Psychology. Psychological Science, 2004, 27 (4), 943-945.

[8] Canter, D. E. Self-appraisals, perfectionism, and academics in college undergraduates. Unpublished doctoral dissertation, Virginia Commonwealth University, U. S. A. 2008.

[9] Rice, K. G., \& Lopez, F. G. Maladaptive perfectionism, adult attachment and self-esteem in college students. Journal of College Counseling, 2004 7(2), pp.118-128.

[10] Rice, K. G., \& Lapsley, D. K. Perfectionism, coping, and emotional adjustment. Journal of College Student Development, 2001, 42(2), pp.157-168

[11] Damian, L. E., Stoeber, J., Negru, O., \& Baban, A. Positive and negative affect in adolescents: An investigation of the $2 \times 2$ model of perfectionism. Cognition, Brain, Behavior. An Interdisciplinary Journal, 2014, 18, pp.1-16.

[12] Slaney, R. B., Rice, K. G., Mobley, M., Trippi, J., \& Ashby, J. The revised almost perfect scale. Measurement and Evaluation in Counseling and Development, 2001, 34(3), pp.130-145.

[13] Beheshtifar, M. Improving achievement motivation: By diminish negative perfectionism. Applied Mathematics in Engineering, Management and Technology, 2013, 1(3), pp.23-28.

[14] Ren Fifi, Liu Guirong, Zhang Jinghuan et al. The Impact of Leadership on Employee Creativity: Based on the Variable-centered and Personcentered Perspectives. Psychological and Behavioral Studies, 2014, 12 (4), pp. 540-545.

[15] Zhao Jingxin, Shen Jiliang, Liu Xia. The Relationship between Social Support Networks and Self-esteem for Left-behind Adolescent and Initiative Communication-Based on the Variable-centered and Person-centered Perspectives. Psychological Science, 2008, 31 (4), pp. 827-831.

[16] Zi Fei, Zhou Xu. Reliability and Validity of the Frost Multidimensiona Perfectionism Questionnaire. Chinese Journal of Clinical Psychology, 2006, 14 (6), pp. 560-563. 